\title{
Prevalence of Sudden Death and Out-of-Hospital Cardiac Arrest in Infants, Children, and Adolescents
}

\author{
- What Does it Imply? -
}

\author{
Masao Yoshinaga, MD, PhD
}

I n January 2005, the Fire and Disaster Management Agency of Japan launched a prospective, nationwide, populationbased cohort study of patients suffering out-of-hospital cardiac arrest (OHCA). ${ }^{1}$ The data from that cohort study have revealed important information about OHCA not only nationally in Japan, ${ }^{1-3}$ but also in selected population such as infants, children, and adolescents ${ }^{4,5}$ in Japan.

\section{Article p 2596}

In this issue of the Journal, Okamoto et al report regional variations in the prevalence and survival rates of OHCA in subjects aged $<1$ year and those aged $1-17$ years. ${ }^{5}$ Concerning the data for prevalence of sudden death in infants, children, and adolescents, Japanese scientists have obtained data from 2 sources. The Injury and Accident Mutual Aid Benefit System of the Japan Sport Council ${ }^{6}$ provides annual data of subjects who suf- fered from sudden cardiac death (SCD) while under school supervision, including deaths that occurred during class hours (including nurseries), as well as during extracurricular hours, during breaks (including before class and after school), or on the way to and from school and/or nurseries. ${ }^{6}$ The Journal of Health and Welfare Statistics ${ }^{7}$ published by the Health, Labour and Welfare Statistics Association, and the almanac of data on Japanese children ${ }^{8}$ published by the Japan Child and Family Research Institute have provided data that include the number of victims of sudden infant death syndrome (SIDS).

The change in the prevalence of SCD caused by cardiac or great artery diseases while under school supervision between 1989 and 2011 is shown in Figure 1A. Statistical analysis using ANOVA and Tukey's test showed that prevalence significantly decreased during 2001-2004 and 2005-2008 (Trend, $\mathrm{P}=0.000$, Figure 1B). This significant decrease in the prevalence of SCD may be, in part, related to the availability of public-access defi-

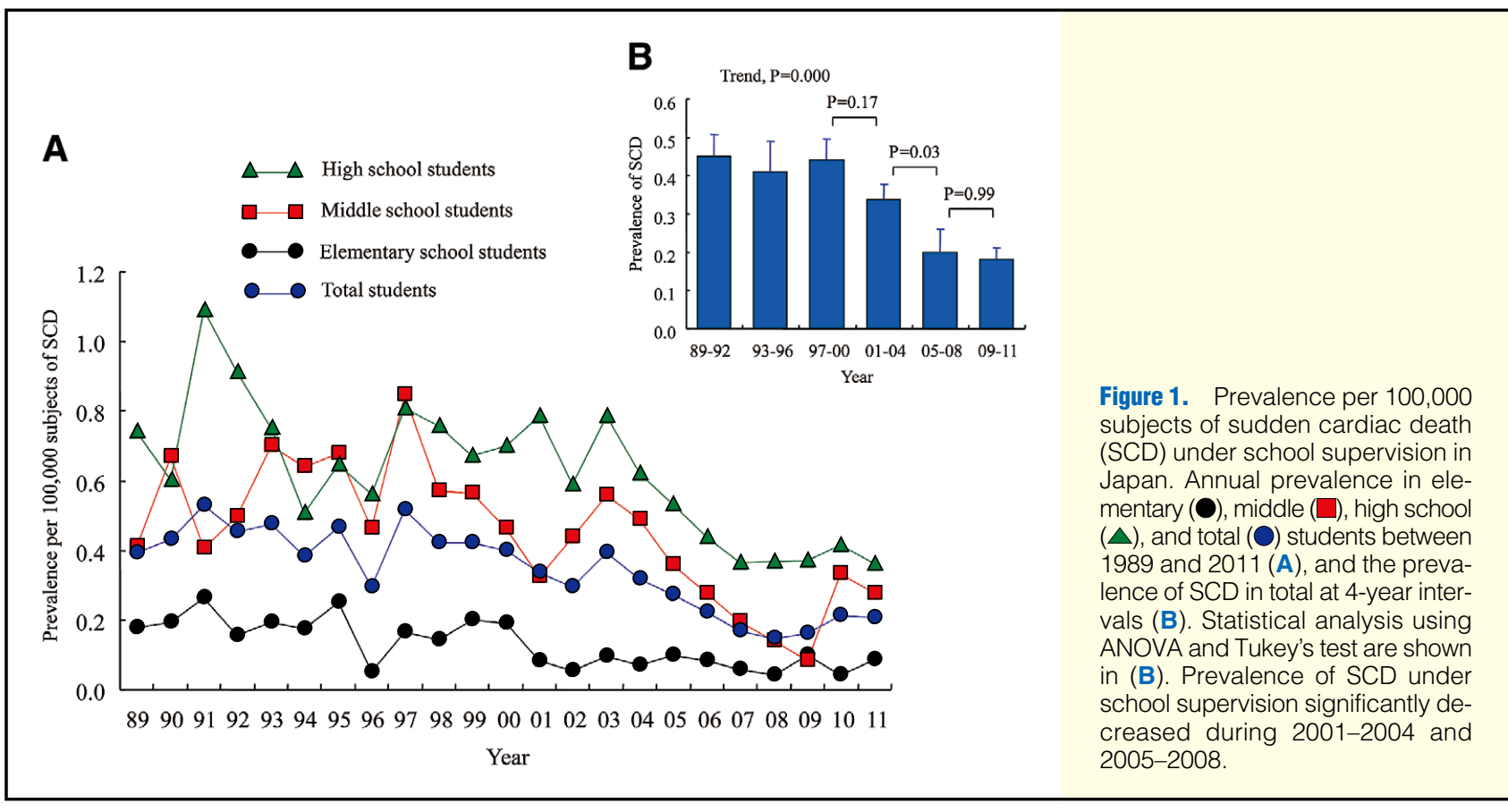

The opinions expressed in this article are not necessarily those of the editors or of the Japanese Circulation Society.

Received August 16, 2013; accepted August 19, 2013; released online September 6, 2013

National Hospital Organization Kagoshima Medical Center, Kagoshima, Japan

Mailing address: Masao Yoshinaga, MD, PhD, Department of Pediatrics, National Hospital Organization Kagoshima Medical Center, shiroyama-cho 8-1, Kagoshima 892-0853, Japan. E-mail: m-yoshi@kagomc2.hosp.go.jp

ISSN-1346-9843 doi:10.1253/circj.CJ-13-1062

All rights are reserved to the Japanese Circulation Society. For permissions, please e-mail: cj@j-circ.or.jp 


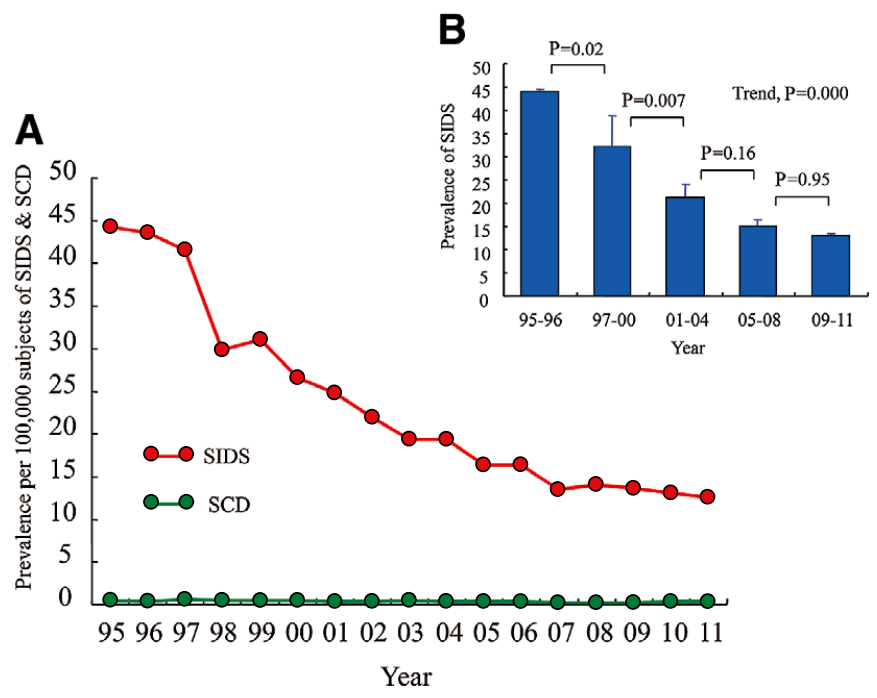

Figure 2. Prevalence per 100,000 subjects of sudden infant death syndrome (SIDS) in Japan. Annual prevalence of sudden infant death syndrome (SIDS) (O) and sudden cardiac death (SCD) (O) under school supervision (A) and prevalence at 4-year intervals (B). Statistical analysis by ANOVA and Tukey's post-hoc test (B). The first and final interval years include the average of 2- and 3-year data to compare with the data shown in Figure 1. (A) Prevalence of SIDS in $2011(12.6 / 100,000)$ was 63-fold higher compared with SCD under school supervision (0.20/100,000). (B) Prevalence of SIDS significantly decreased during 1995-1996 and 2001-2004.

brillators. Use of an automated external defibrillator (AED) by the public has been legal in Japan since July $1,2004 .^{1-5}$ Prehospital return of spontaneous circulation and survival at 1 month significantly improved from 2005 to 2009 among elementary and middle school students with OHCA. ${ }^{4}$ One finding of concern, for which a reason needs to be determined, was the sharp increase in the prevalence of SCD in middle-school students in 2010.

Akahane et al recently published data regarding pediatric OHCA by scholastic category of infants, preschool children, elementary, middle, and high school students between 2005 and 2008. ${ }^{9}$ Their data enable us to compare data concerning SCD under school supervision with OHCA among students. The number of students in elementary, middle, and high school who died suddenly while under school supervision between 2005 and 2008 was 20,35 , and 63, respectively, and the prevalence was $0.070,0.241$, and 0.434 , respectively. In contrast, the number of subjects who suffered from cardiac causes of OHCA in elementary, middle, and high school between 2005 and 2008, according to data from Akahane et al, was 242, 186, and 271, respectively, and the prevalence was $0.842,1.279$, and 1.868 per 100,000 subjects, respectively. ${ }^{9}$ The prevalence of OHCD was 12.1-, 5.3-, and 4.3-fold, respectively, that of SCD under school supervision.

The prevalence of SIDS in Japan is shown in Figure 2A. Statistical analysis showed that prevalence significantly decreased during 1995-1996 and 2001-2006 (Trend, P=0.000, Figure 2B). The number of infants and the prevalence of SIDS between 2005 and 2008 were 651 and 15.0/100,000, respectively. However, the number and prevalence of infants who suffered OHCA were much higher during the same periods: 1,773 and 40.9/100,000 infants respectively. ${ }^{9}$

The exact nature of cardiac arrest among infants, children, and adolescents is still unknown. To aid research into the nature of cardiac arrest among these groups, both conventional (SCD under school supervision and SIDS) and OHCA data should be closely monitored. The data from Okamoto et al also show regional variations in survival following pediatric OHCA. ${ }^{5}$ Thus, more detailed data concerning pediatric OHCA, namely annual changes in prevalence and outcomes of OHCA among infants, preschool children, elementary, middle, and high school students is needed. Longitudinal changes in regional differences should also be provided. Unfortunately Okamoto et $\mathrm{al}^{5}$ and others ${ }^{4}$ have not be able to show the exact reason(s) for the regional differences in the prevalence and outcomes of OHCA. However, accumulation of more detailed data may illuminate this issue. Each individual case should be further investigated to determine any confounders present in each area to prevent locally occurring OHCA, and finally, to decrease the nationwide prevalence of OHCA. An advantage in Japan is the presence of a nationwide school-based ECG screening program for cardiovascular diseases. It has been established for all $1 \mathrm{st}, 7 \mathrm{th}$, and 10th graders in Japan since 1994. Combination and further analyses of conventional and OHCA data regarding SCD/ cardiac arrest and data from the school-based screening program will improve the prevalence and outcomes in the near future in Japan. It depends on our efforts.

\section{References}

1. Kitamura T, Iwami T, Kawamura T, Nitta M, Nagao K, Nonogi H. Nationwide improvements in survival from out-of-hospital cardiac arrest in Japan. Circulation 2012; 126: 2834-2843.

2. Hasegawa K, Tsugawa Y, Camargo CA Jr, Hiraide A, Brown DF. Regional variability in survival outcomes of out-of-hospital cardiac arrest: The All-Japan Utstein Registry. Resuscitation 2013; 84: 10991107.

3. Sasaki M, Iwami T, Kitamura T, Nomoto S, Nishiyama C, Sakai T, et al. Incidence and outcome of out-of-hospital cardiac arrest with public-access defibrillation. A descriptive epidemiological study in a large urban community. Circ J 2011; 75: 2821-2826.

4. Mitani Y, Ohta K, Yodoya N, Otsuki S, Ohashi H, Sawada H. Public access defibrillation improved the outcome after out-of-hospital cardiac arrest in school-age children: A nationwide, population-based, Utstein registry study in Japan. Europace 2013 Apr 19, doi:10.1093/ europace/eut053 [Epub ahead of print].

5. Okamoto Y, Iwami T, Kitamura T, Nitta M, Hiraide A, Morishima $\mathrm{T}$, et al. Regional variation in survival following pediatric out-ofhospital cardiac arrest. Circ J 2013; 77: 2596-2603.

6. Death and injury while under school supervision (in Japanese, data from 2005 was available at http://www.jpnsport.go.jp/anzen/anzen school/back/tabid/296/Default.aspx (accessed on August 13, 2013).

7. Journal of Health and Welfare Statistics. Health, Labour and Welfare Statistics Association. The data between 1995 and 2011 were used.

8. Almanac of data on Japanese children. Japan Child and Family Research Institute (JCFRI). http://www.aiiku.or.jp/index.htm (accessed on August 13, 2013).

9. Akahane M, Tanabe S, Ogawa T, Koike S, Horiguchi H, Yasunaga H. Characteristics and outcomes of pediatric out-of-hospital cardiac arrest by scholastic age category. Pediatr Crit Care Med 2013; 14: $130-136$. 